Article

\title{
The Effect of Silica-Filler on Polyurethane Adhesives Based on Renewable Resource for Wood Bonding
}

\author{
Mariusz Ł. Mamiński ${ }^{1}{ }^{*}$, Anna M. Więcław-Midor ${ }^{2}$ (D) and Paweł G. Parzuchowski ${ }^{2}$ (D) \\ 1 Institute of Wood Sciences and Furniture, Warsaw University of Life Sciences-SGGW, \\ 159 Nowoursynowska St., 02-776 Warsaw, Poland \\ 2 Faculty of Chemistry, Warsaw University of Technology, 3 Noakowskiego St., 00-664 Warsaw, Poland; \\ awieclaw@ch.pw.edu.pl (A.M.W.-M.); pparzuch@ch.pw.edu.pl (P.G.P.) \\ * Correspondence: mariusz_maminski@sggw.edu.pl; Tel.: +48-22-593-85-27
}

Received: 20 July 2020; Accepted: 22 September 2020; Published: 24 September 2020

\begin{abstract}
The aim of the study was to evaluate the applicability and performance of polyglyceroland sucrose-based polyols as components of a simplified formulation of polyurethane adhesives. Colloidal silica was used as a viscosity control and reinforcing agent. The adhesives were examined in terms of reactivity, thermal stability, viscosity, work of adhesion, wetting, surface energy, and bonding strength on wooden substrates. Silica was found to increase gelling time, but markedly improved bonding strength and adhesion with substrates. Bonded solid beech wood samples prepared at 80,110 , and $130^{\circ} \mathrm{C}$ showed shear strengths between $7.1 \mathrm{MPa}$ and $9.9 \mathrm{MPa}$ with $100 \%$ wood failure. The renewable resource-based polyols were demonstrated to be useful in formulation of polyurethane adhesives for furniture industry — especially with silica as a filler.
\end{abstract}

Keywords: biopolyol; polyurethane adhesive; glycerol; sucrose

\section{Introduction}

The research on bio-based or bio-derived adhesives and polyurethanes has been carried out for years [1-8]. Since Anastas and Warner [9] stated twelve principles of green chemistry, the investigations in the field of cleaner production have intensified. One of the most important classes of adhesives is polyurethanes (PURs) that are widely used in wood and furniture industries. Therefore, it is important to increase the content of bio-based components in PUR adhesives-preferably by substitution of petroleum-based polyols with renewable feedstock-derived ones.

The convenient feedstock are glycerol and sucrose. The former is a by-product from vegetable oils transformations to biodiesel $[10,11]$ and the latter is produced in large amounts from sugarcane or sugar beet. Due to their renewability, bio-origin, low cost, and availability, both glycerol and sucrose have great potential as raw material for the development of new classes of polyurethanes [12-14]. Incorporation of disaccharides into polyurethane structure results in enhanced hydrolysis in soil which promotes biodegradation [15]. It is also anticipated that the demand on industrial sugar will increase in world markets [16]. Therefore, new ways of industrial use of sucrose should be investigated. The current trends in the adhesives for furniture sector are formaldehyde-free adhesives $[17,18]$, sucrose-based adhesives [19,20], and renewable resource-based polyurethanes [21,22]. Depletion of petroleum supplies, the fluctuating prices and environmental problems which associated with oil industry, make renewable, plant-derived resources more and more attractive for this class of adhesives [23]. Biopolyols are excellent substitutes for petroleum-derived polyols as long as the resultant PURs of high renewable content exhibit properties comparable to traditional ones. Unlike for structural applications, adhesives dedicated to furniture manufacturing-especially for veneering of medium density fiberboards or particleboards—are not required to exhibit very high strength as the 
surface soundness of these materials typically varies between $0.8 \mathrm{MPa}$ and $1.6 \mathrm{MPa}$ depending on the density of a panel [24-26]. No lower limit for the bondline strength in the substrate-adhesive-veneer system is defined. Instead, in practice, a visual analysis of the edge after machining is used for the evaluation of bond quality.

Thus, it was hypothesized that 2-component PUR adhesives of a simplified formulation limited to one biopolyol and one diisocyanate would exhibit properties sufficient for veneering in furniture manufacturing, as well as, decrease the cost of an adhesive.

A great advantage of polyurethanes is the ease to tailor their properties to a specific area of application such as foams, coatings, or 1- and 2-component adhesives. A formulated adhesive contains a number of components: Isocyanates, a mixture of polyols, catalysts, chain extenders, tackifiers, fillers, and other additives $[27,28]$. The use of multi-component formulations is to provide an adhesive with high strength, resistance to chemical and physical factors, as well as a long-term durability in service, which is fully justified when adhesive is dedicated to structural applications in construction or engineered wood products.

In this study two PUR adhesives containing polyglycerol- or sucrose-based polyols were investigated for their application in wood bonding. Industrially feasible adhesives have to meet the requirements such as practical reactivity, viscosity, and bonding strength. These properties have to be tuned for each newly developed binder. The proposed adhesives are expected to be used in veneering in furniture industry. However, the initial experiments indicated that their physical and chemical properties had to be adjusted. The reactivity was adequate, but the low viscosity was a concern due to adhesive overpenetration through a veneer.

It is well studied that silica filler in a polymeric matrix may contribute to increase in mechanical strength and fracture toughness by the mechanism of crack tip blunting or crack pinning [29-32]. It was shown that doping of polymer composites with nanosilica may be an efficient way to enhancement of their strength and toughness [33]. Silica particles have also been proved to increase adhesion and surface energy of a polyurethane as well as to modify its rheological behavior [27,34]. Improvement of properties like Young's modulus [35], storage, and loss moduli of a polyurethanes have also been reported [34].

In the present work, the effect of using the colloidal silica as the filler on the reactivity, viscosity, thermal stability, and adhesive interactions were examined and discussed.

\section{Materials and Methods}

\subsection{Materials}

Two biopolyols were examined as components for PUR wood adhesives: A-polyglycerol synthesized by ring opening polymerization of glycerol carbonate and 1,1,1-tris(hydroxymethyl)propane (TMP) at 6/1 molar ratio [36,37]. The product was a highly viscous light-brown liquid. NMR spectrum was recorded on a Varian VXR $400 \mathrm{MHz}$ (Palo Alto, CA, USA). ${ }^{1} \mathrm{H}$ NMR (400 MHz, DMSO- $\left.d_{6}\right), \delta(\mathrm{ppm}): 4.91-4.20\left(\mathrm{~m}, 10 \mathrm{H}, \mathrm{H}_{2} \mathrm{O}, \mathrm{OH}\right), 3.75-3.10$ ( $\mathrm{m}, 38 \mathrm{H}$, polyether backbone), $1.36-1.16$ (bs, $\underline{\mathrm{CH}}_{2} \mathrm{CH}_{3}$ ), 0.77 (bs, $\mathrm{CH}_{2} \underline{\mathrm{CH}}_{3}$ )—see Figure S1. GPC in water: $M_{\mathrm{n}}=563.47, M_{\mathrm{w}}=1036.63, D=1.83$ (Viscotek (Malvern Panalytical Ltd., Malvern, UK) system with a triple detector array (TDA) 305 and divinylbenzene (DVB) Jordi column (JordiLabs LLC, Mansfield, MA, USA). It is a structural analogue of the polyglycerol characterized in our previous work [37]. The other commercial sucrose-based polyether polyol labeled as C was manufactured by Oltchim (Valcea, Romania) and used as obtained. Basic properties of the polyols are shown in Table 1. Polymeric methylenediphenyldiisocyanate (PMDI) was purchased from Huntsman Co., (Arlington, TX, USA) and used as received. Isocyanate content in PMDI was $36 \%$, with $4,4^{\prime}$ MDI isomer content lower than $75 \%$. The viscosity of PMDI is $290 \mathrm{mPa} \cdot \mathrm{s}$ at $20{ }^{\circ} \mathrm{C}$, and average functionality 2.7. Viscosity of the adhesives was controlled by addition of colloidal hydrophilic silica $\left(\mathrm{SiO}_{2}\right.$, surface area $200 \pm 25 \mathrm{~m}^{2} / \mathrm{g}$ manufactured by Evonik Industries $\mathrm{AG}$, 
Essen, Germany) as a filler: $2.0 \mathrm{wt} \%$ for in polyol $\mathrm{A}$ and $6.0 \mathrm{wt} \%$ for polyol $\mathrm{C}$ were needed to reach practical viscosity.

Table 1. Selected physical and chemical properties of the studied polyols.

\begin{tabular}{ccccc}
\hline Polyol & $\begin{array}{c}\text { Hydroxyl Number } \\
\text { [mg KOH/g] }\end{array}$ & $\begin{array}{c}\text { Hydroxyl } \\
\text { Functionality }\end{array}$ & \multicolumn{2}{c}{$\begin{array}{c}\text { Viscosity at } 25{ }^{\circ} \mathbf{C} \\
\text { [Pa-s] }\end{array}$} \\
\hline- & - & - & Non-filled & $\mathrm{SiO}_{2}$-filled \\
$\mathrm{A}$ & 694 & $9^{\mathrm{a}}$ & 10 & 400 \\
$\mathrm{C}$ & 425 & 5 & 0.70 & 275 \\
\hline
\end{tabular}

\subsection{Adhesive Formulation}

PMDI and polyols were used in formulation of 2-component PUR adhesives. The amounts of the components were calculated from the Equation (1):

$$
m_{\text {iso }}=\left(\frac{\sum m_{\text {polyol }} \times L_{O H}}{56100}\right) \times \frac{4202}{c_{\text {iso }}}
$$

where: $m_{i s o}$ - stoichiometric amount of isocyanate in grams, $m_{\text {polyol }}$-amount of polyol in grams, $\mathrm{L}_{\mathrm{OH}}$ - polyol hydroxyl number in $\mathrm{mg} \mathrm{KOH} / \mathrm{g}, c_{i s o}-\mathrm{NCO}$ content in PMDI in wt $\%$. Target NCO/OH index was 1.0. The components were weighted in a plastic cup and mixed for $5 \mathrm{~s}$ at $500 \mathrm{rpm}$ speed. In the case of $\mathrm{SiO}_{2}$-filled polyols, the filler was mixed with a polyol prior to adhesive formulation.

\subsection{Lap Shear Strength}

Bondline shear strength tests were done according to EN 205 [38]. Beech (Fagus sylvatica) wood of density $700 \pm 50 \mathrm{~kg} / \mathrm{m}^{3}$ and $5 \%$ moisture content was used as the substrate. Adhesives were applied at $200 \mathrm{~g} / \mathrm{m}^{2}$ rate and bonded at 80,110 , and $130{ }^{\circ} \mathrm{C}$ for 7 min under $0.8 \mathrm{MPa}$ pressure.

Bonded specimens (Figure 1) were conditioned at normal conditions $\left(20 \pm 2{ }^{\circ} \mathrm{C}\right.$ and $65 \pm 5 \%$ relative humidity) for 7 days before testing. Twelve specimens were tested in each series.

Shear strength $\left(R_{t}\right)$ was calculated using the Equation (2):

$$
R_{t}=\frac{F_{\max }}{S}
$$

where: $F_{\max }$ - the maximum force in Newtons, $S$-lap area in $\mathrm{mm}^{2}$.

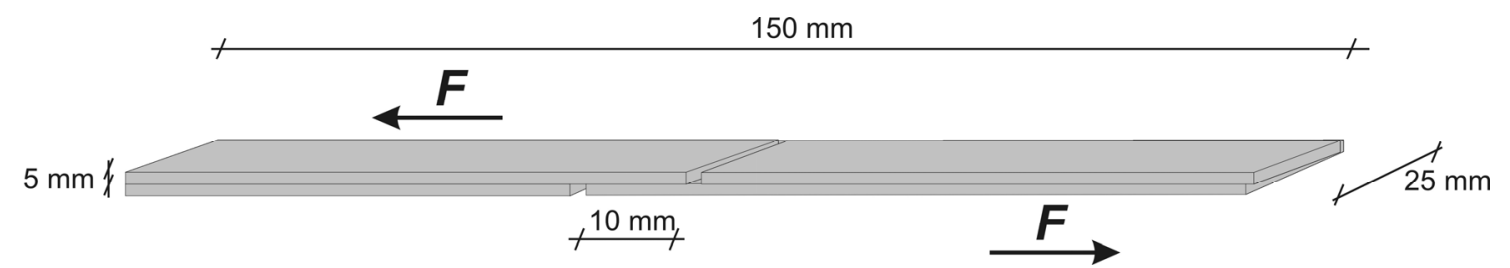

Figure 1. Lap specimen: F-force direction.

\subsection{Pull-Off Adhesion Test}

Veneer pull-off tests were performed according to [39] on natural 0.6-mm thick oak veneer bonded to medium density fiberboard (MDF) with the studied adhesives based on polyol A or polyol $\mathrm{C}\left(65^{\circ} \mathrm{C}\right.$, 1.0 MPa, 4 min). A Positest ${ }^{\circledR}$ AT-A pull-off adhesion tester (DeFelsko Corp., Ogdensburg, NY, USA) equipped with 20-mm dollies was used (Figure 2). 


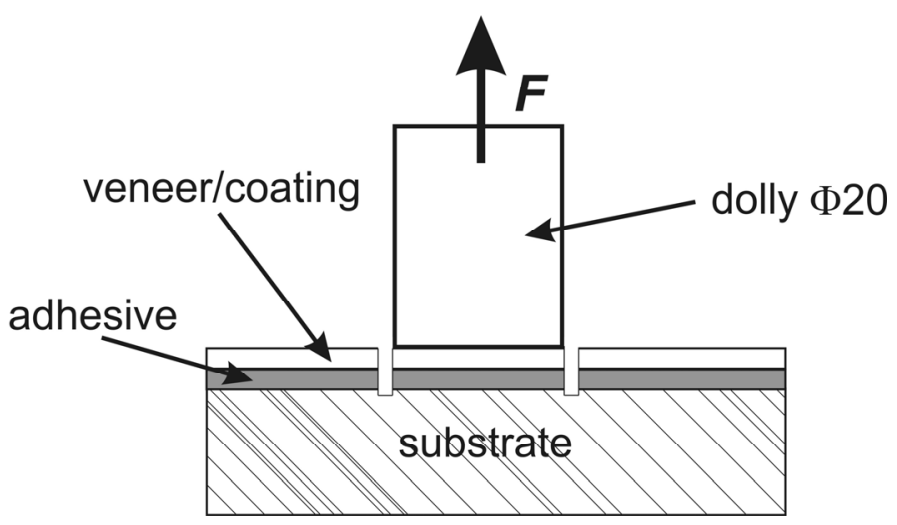

Figure 2. Pull-off specimen: F-force direction.

\subsection{TG-MS Experiments}

Thermogravimetric analyses were performed on a STA 449C (Netzsch, Selb, Germany) instrument coupled with QMS 403C (Netzsch, Selb, Germany) mass spectrometer in air $\left(\mathrm{N}_{2} / \mathrm{O}_{2} 79: 21, v / v\right)$ at constant heating rate $10{ }^{\circ} \mathrm{C} / \mathrm{min}$ to $800{ }^{\circ} \mathrm{C}$. Polymer sample of $0.0001 \mathrm{~g}$ and $0.25 \mathrm{~g}$ calcinated $\mathrm{Al}_{2} \mathrm{O}_{3}$ were placed on $\mathrm{Al}_{2} \mathrm{O}_{3}$ pan to avoid uncontrolled spill.

MS instrument recorded $\mathrm{m} / \mathrm{z}$ of the ions in the range 10-300 Da during thermogravimetric experiments.

\subsection{Contact Angle $(\theta)$, Surface Free Energy $(\gamma)$, and Work of Adhesion $\left(W_{a}\right)$}

A Phoenix 300 contact angle analyzer (Surface Electro Optics, SuwonCity, Korea) equipped with microscopic lenses and digital camera was used. The sessile droplet method was used for contact angle and work of adhesion measurements. Distilled water and diiodomethane were used as two reference liquids. The average contact angles are means of 5 measurements done $60 \mathrm{~s}$ since droplet deposition. Calculations of surface free energy were based on the Owens-Wendt method [40]. Work of adhesion between wetting liquid (water) and PUR was calculated from the Equation (3) [40]:

$$
W_{a}=\gamma_{S}+\gamma_{L}-\gamma_{S L}
$$

where: $\gamma_{S}$ is the surface energy of solid, $\gamma_{L}$ is the surface tension of liquid, $\gamma_{S L}$ is the interfacial tension between a solid and a liquid (Equation (4)):

$$
\gamma_{S L}=\gamma_{S}+\gamma_{L}-2 \sqrt{\gamma_{S}^{D} \gamma_{L}^{D}-2 \sqrt{\gamma_{S}^{P} \gamma_{L}^{P}}}
$$

where $D$ and $P$ superscripts refer to dispersive and polar parts of free surface energy. Values for liquids for calculations are presented in Table 2.

Table 2. Surface tension components of the reference liquids $\left(\mathrm{mJ} / \mathrm{m}^{2}\right)$ [41].

\begin{tabular}{cccc}
\hline Liquid & $\gamma$ & $\gamma^{\mathbf{D}}$ & $\gamma^{\mathbf{P}}$ \\
\hline Diiodomethane & 50.80 & 50.80 & 0.00 \\
Water & 72.80 & 21.90 & 51.00 \\
\hline
\end{tabular}

\section{Results and Discussion}

\subsection{Effect of Viscosity on Bonding}

In our initial experiments with PUR adhesives based on glycerol- or sucrose-derived polyols, the viscosities of the formulations without $\mathrm{SiO}_{2}$ were too low (1.2 Pa.s and $5.5 \mathrm{~Pa} \cdot \mathrm{s}$ for $\mathrm{C}$ polyol-based 
and A polyol-based, respectively) which resulted in overpenetration of the adhesive through a 0.6-mm thick oak veneer. Thus, surface staining occurred (Figure 3). In order to overcome the problem, the viscosity was adjusted to a practical range by using colloidal silica as the viscosity control agent. It showed that both the addition of $2 \%$ silica in A-polyol and $6 \%$ silica in C-polyol resulted in a remarkable increase in the viscosities of the polyols (Table 1), while resultant viscosities of the formulated 2-component adhesives were 19.7 Pa.s and 37.0 Pa.s, respectively, for C polyol-based and A polyol-based PURs. Increased viscosity produced thixotropy or pseudoplastic behavior [34], which subsequently, helped to avoid the adhesive overpenetration (Figure 3).
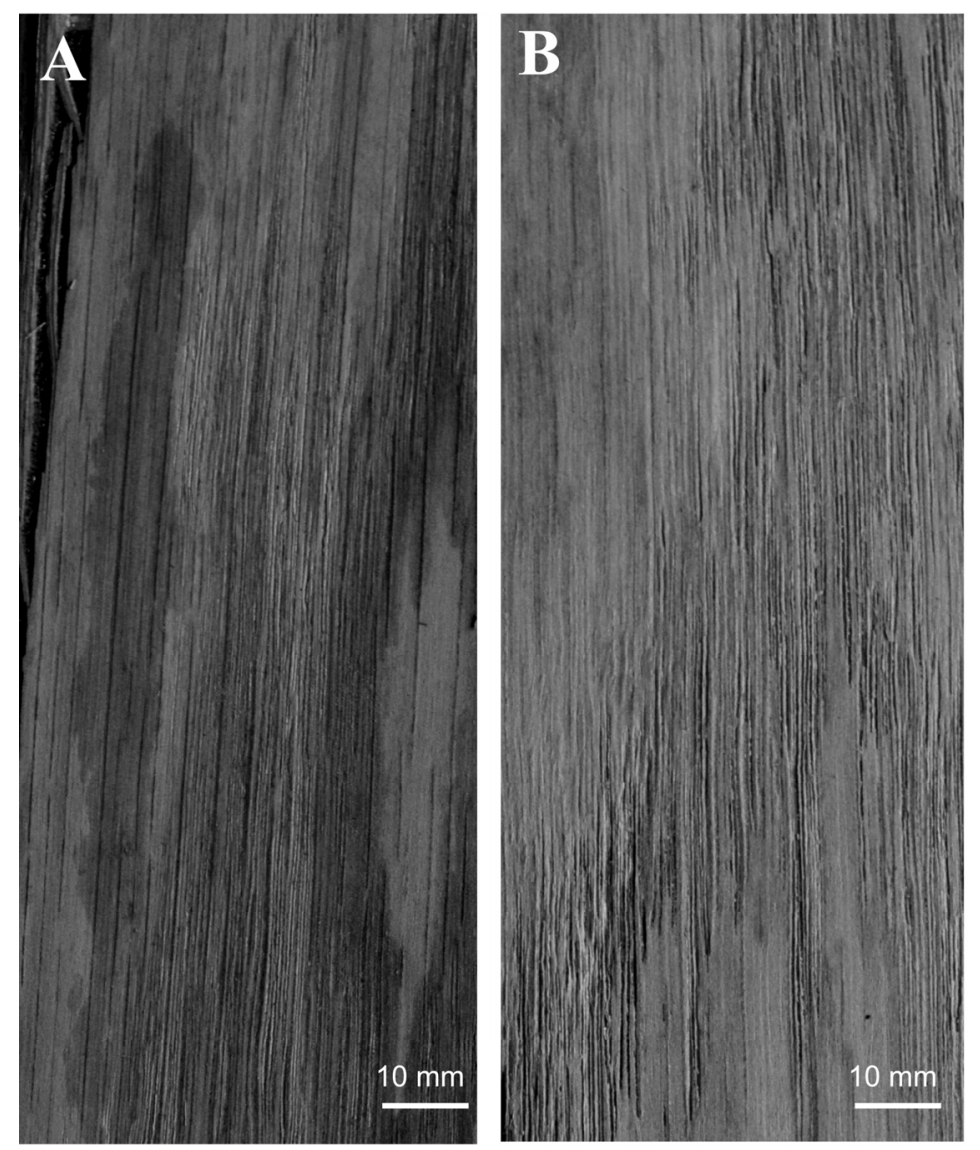

Figure 3. 0.6-mm thick oak veneer surface: (A) adhesive overpenetration and staining (polyurethane (PUR) without $\mathrm{SiO}_{2}$ ), (B) avoided staining (PUR with $\mathrm{SiO}_{2}$ ).

\subsection{Reactivity}

Data in Table 3 indicate the studied adhesive formulations exhibit sufficient reactivity at ambient temperature, as the gelling times between 10 and $15 \mathrm{~min}$ at $20^{\circ} \mathrm{C}$ is a practical range for solid wood bonding in industry. As it was shown previously, the reactivity of the polyglycerol-based PUR systems can be easily controlled by the type and amount of catalyst used. Thus, set times as short as 1 min can be obtained [37]. However, highly reactive binders are useful only in automatic bonding lines to keep high production capacity-e.g., veneering in furniture industry.

It is worth to mention that, the addition of the $\mathrm{SiO}_{2}$ filler decreased the reactivity of PUR. The gelling times at ambient temperature were increased by $17 \%$ and $250 \%$ for the branched polyglycerol $\mathrm{A}$ and the sucrose-based polyol C, respectively. This was caused by the difference amount of silica added, since polyol A was doped with $2 \%$, due to its innate high viscosity, while polyol C was added $6 \%$ silica. Apparently, strong $\mathrm{H}$-bonding interactions between polyol molecule and $\mathrm{SiO}_{2}$ might have been the main reason of slowing down in the gelling/curing. The observed slowing down of gelling is accordant to the literature data on the thermal effects of PUR curing in the presence of silica. It had 
been proved that even small additions resulted in a few-fold decrease in enthalpy of curing, thus, the process was hampered and required higher temperature to full conversion [27]. Also, Chiacchiarelli and co-workers demonstrated that nanosilica additions resulted in a decreased the rate constant for curing by ca. $60 \%$, reduced thermal effect and a shift of heat flow peak in DSC curves to higher temperatures [42]. Curing kinetics of the polyglycerol-PMDI systems were described elsewhere [43]. The observed thermal effects depend on the abundancy of hydroxyl groups in a molecule and range between ca. $12 \mathrm{~J} / \mathrm{g}$ and $50 \mathrm{~J} / \mathrm{g}$, while heat flow peak appears about $67-69^{\circ} \mathrm{C}$.

Since veneering usually is performed at the temperature close to $100{ }^{\circ} \mathrm{C}$, high reactivity of the PUR adhesives allows fast processing, and, makes possible to get one-cycle pressing time as short as 30-60 s under industrial conditions.

Table 3. Gelling time at $20^{\circ} \mathrm{C}$ for polyglycerol- and sucrose-based PUR adhesives (NCO/OH ratio 1.0).

\begin{tabular}{ccc}
\hline Polyol & $\mathbf{S i O}_{2}$-Filler Addition[wt $\%$ ] & Gelling Time[s] \\
\hline $\mathrm{A}$ & 0 & 510 \\
$\mathrm{~A}$ & 2.0 & 600 \\
$\mathrm{C}$ & 0 & 600 \\
$\mathrm{C}$ & 6.0 & 2100 \\
\hline
\end{tabular}

\subsection{Bondline Shear Strength}

It is clear from the analysis of shear strength of the bondlines in solid wood (Figure 4) that pressing temperature does not have remarkable effect on that parameter neither for A nor for $\mathrm{C}$ polyol-based adhesive. Thus, bonding can be performed at either temperature without significantly different results. However, due to low strengths of the A polyol-based PUR without $\mathrm{SiO}_{2}(1.8-2.8 \mathrm{MPa})$ (Figure 4) its applicability in veneering is discrepant, so that-keeping in mind that the practical surface soundness of particleboard ranging from 0.8 to $1.6 \mathrm{MPa}[26,39,44]$ —evaluation in pull-off test is necessary. Comparable shear strengths $(2.84 \mathrm{MPa}$ with high rate of substrate failure were reported by Tenorio-Alfonso and co-workers [22] for the adhesives derived from cellulose acetate, 1,6-hexamethylene diisocyanate and castor oil with renewable content as high as $70 \%$. Similar results were achieved for hot melt reactive polyurethanes derived from $\mathrm{CO}_{2}$-based poly(propylene carbonate): Lap-shear tests performed after 7-day curing on aluminum and steel revealed maximum strengths, respectively, 5.5 MPa and 4.7 $\mathrm{MPa}$ [45] and 1.5-6.0 MPa for plastics [46]. PUR adhesives based on biopolyols from liquefied biomass were proved to exhibit comparable performance as the shear strengths ranged between 5.8 and $11.0 \mathrm{MPa}$ [21].

On the other hand, addition of silica had more apparent effect on bonding strength. The comparison of the values for non-SiO${ }_{2}$-filled and $\mathrm{SiO}_{2}$-filled adhesive formulations revealed significant increase in shear strength, but the effect was more evident for A polyol-based adhesive of low innate strength: 1.8-2.8 MPa and 7.2-7.5 MPa for non-filled and filled, respectively. A lower performance of the A polyol-based adhesive without $\mathrm{SiO}_{2}(\mathrm{~A} 0 \%$ series $)$ can be attributed to dense crosslinking due to A polyol hydroxyl functionality as high as 9 which renders brittleness and low mechanical properties. Dispersed silica presence resulted in improving of the mechanical properties of the adhesive (A2\% series) according to the mechanisms reported in $[29,32]$. Unlike the A-series, the $C$ polyol-based adhesive in shear strength tests was not apparently affected by silica addition. The used wood substrate- though conforming the standards-did not allow measure true strength of the adhesive. The observed 1.7- to 3-fold enhancement as well as high substrate failure rate indicate that the approach was more effective than that reported for thermoplastic PURs composites [34] or nanosilica-filled PUR adhesive where 8\% gain was achieved [27] and coherent with the results obtained for acrylic-polyurethane coatings doped with $4-6 \%$ nanosilica where $40 \%$ enhancement in adhesion was yielded [47]. Worth mentioning is that the performance of the $\mathrm{SiO}_{2}$-filled PURs is comparable to that of the commercial adhesives not containing bio-derived components-i.e., PUR 6.25 MPa (100\% substrate failure) [48]. The phenomenon can be explained: (1) by the development of the hydrogen bonds between the hydroxyl groups of the 
nanoparticles and the carbonyl groups of the polyurethane [49] which intensifies interfacial forces and is accordant with the chemical bonding theory of adhesion and (2) by the role of the filler in fracture formation. According to the crack pinning mechanism, rigid particles impede crack propagating, so that fracture toughness of a filled adhesive is increased [30,31]. The effect was not manifested for the polymer of high innate strength-i.e., PUR based on polyol C (Figure 4). Strengthening effect of small additions of silica on the mechanical properties of polyurethanes remains in accordance with the results reported in recent literature [50,51].

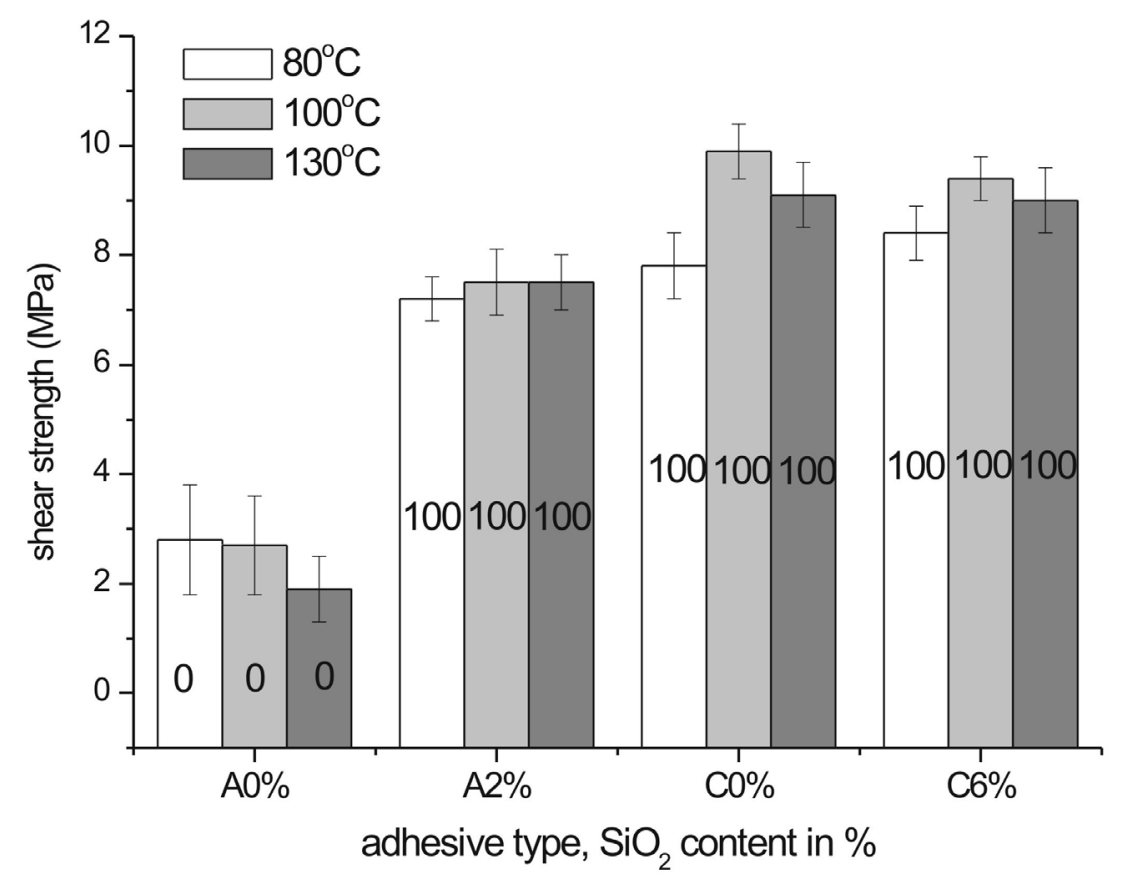

Figure 4. Bondline shear strength of the studied PUR adhesives in solid wood bonded at $80^{\circ} \mathrm{C}, 110^{\circ} \mathrm{C}$, or $130{ }^{\circ} \mathrm{C}$. Numbers denote percentage of substrate failure (see Figure S2).

\subsection{Wetting and Surface Properties}

As the analyses of contact angle, surface free energy and work of adhesion indicate the addition of $\mathrm{SiO}_{2}$ resulted in a lower water contact angle (Figure 5) and increased work of adhesion (Table 4). A $17.9 \%$ increase in $W_{a}$ was observed for the C-based PUR and $23.6 \%$ for the A-based PUR. In this work, the contact angles for water due to silica addition were $23^{\circ}-27^{\circ}$, while that observed for nanosilica-filled PURs reported in [27] was $53^{\circ}-67^{\circ}$ as well as surface free energy enhanced $44 \%$ which is 2-times that found in the literature for PURs with nanosilica doped at a comparable level (4.1 $\mathrm{wt} \%)$.

Work of adhesion values are slightly higher to those reported for water-beech or water-oak wood interactions $\left(126-133 \mathrm{~mJ} / \mathrm{m}^{2}\right)$ [40]. As interactions between PUR and water are enhanced and water is considered the model of a polar phase, it can be inferred that PUR interactions with hydrophilic wood surface containing high concentration of $\mathrm{OH}$ groups (ca. $10^{21}$ groups per gram [52]) are also enhanced. The phenomenon confirms that filling the adhesive with $\mathrm{SiO}_{2}$ was beneficial for adhesion between veneer and adhesive and the observed changes in surface properties promote adhesive interactions. The significance of substrate/adhesive surface energy relation on the adhesion forces has been recognized and associated with interfacial tension [40,53]. As Equation (3) indicates $W_{a}$ is maximized when the interfacial tension $\gamma_{S L}$ is equal zero. Thus, as silica addition induced an increase in PUR surface energy, the interfacial tension $\gamma_{S L}$ was lowered and, subsequently, work of adhesion increased, which resulted in increased PUR/substrate interactions. 


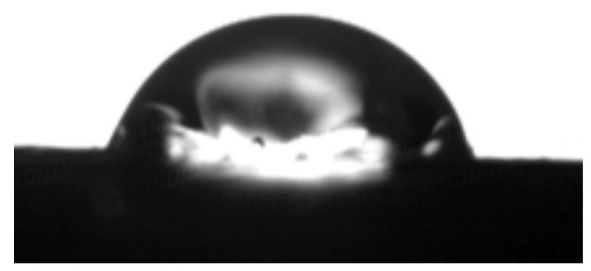

$\mathrm{A} 0 \% \mathrm{SiO}_{2}$

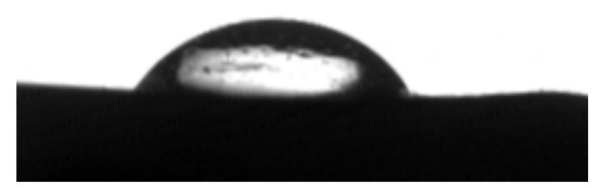

$\mathrm{C} 0 \% \mathrm{SiO}_{2}$

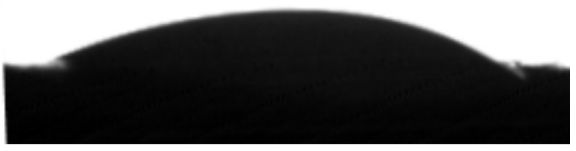

$\mathrm{A} 2 \% \mathrm{SiO}_{2}$

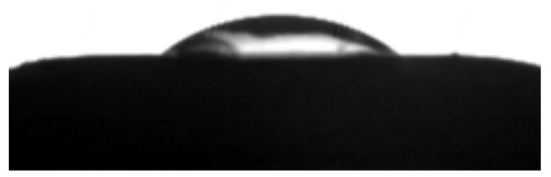

C $6 \% \mathrm{SiO}_{2}$

Figure 5. Water contact angle for non- $\mathrm{SiO}_{2}$-filled and $\mathrm{SiO}_{2}$-filled PURs $60 \mathrm{~s}$ after droplet deposition.

Table 4. Wetting, surface energy and work of adhesion of the studied PURs.

\begin{tabular}{llcccc}
\hline \multirow{2}{*}{ Characteristics } & \multicolumn{4}{c}{ Polyol Used } \\
\cline { 2 - 6 } & \multicolumn{1}{c}{$\mathbf{A 0 \% ~}$} & $\mathbf{A i O}$ & $\mathbf{A 2} \% \mathbf{S i O}_{\mathbf{2}}$ & $\mathbf{C 0 \%} \mathbf{S i O}_{\mathbf{2}}$ & $\mathbf{C 6}_{\mathbf{2}} \mathbf{S i O}_{\mathbf{2}}$ \\
\hline \multirow{2}{*}{ contact angle $\theta\left[{ }^{\circ}\right]$} & water & $56.9 \pm 2.3$ & $23.1 \pm 4.0$ & $53.5 \pm 1.6$ & $27.7 \pm 0.7$ \\
surface free energy $\left[\mathrm{mJ} / \mathrm{m}^{2}\right]$ & diiodomethane & $45.3 \pm 2.4$ & $17.8 \pm 0.3$ & $38.1 \pm 0.9$ & $38.0 \pm 2.2$ \\
work of adhesion $\left[\mathrm{mJ} / \mathrm{m}^{2}\right]$ & & $51.7 \pm 2.0$ & $75.0 \pm 1.3$ & $55.0 \pm 1.7$ & $70.7 \pm 1.8$ \\
\hline
\end{tabular}

\subsection{Pull-Off Adhesion Test}

In order to assess the applicability of adhesives in veneering, a good bond in pull-off test is even more important than that in the lap shear strength. It showed that a significant increase in bonding between a veneer and a substrate can be induced by silica addition. The effect is apparent as the investigated adhesives that exhibit innate low strengths. It is worth to mention that the adhesives for veneering are not required to render substrate failure (MDF/particleboard). It is desirable, but not required by any European standard. The bonding strengths of both investigated PURs (A2\% vs. $\mathrm{A} 0 \%$ and $\mathrm{C} 6 \%$ vs. $\mathrm{C} 0 \%$ ) are shown in Figure 6. The revealed improvement in pull-off adhesion tests remains in accordance with the increased work of adhesion and surface free energy of the adhesive with $\mathrm{SiO}_{2}$ (Table 4). Thus, the enhanced bonding between wooden materials and the silica-filled PURs has been clearly demonstrated. The values shown in Figure 6 are comparable or slightly lower to those achieved for commercial non-renewable-based PUR (2.50 MPa) [22].

One can notice a poor performance of the C0\% PUR in the pull-off test (Figure 6), while the strengths observed in the lap shear tests were satisfactory (100\% substrate failure) (Figure 4$)$. A possible explanation can low viscosity $\left(1.2 \mathrm{~Pa} \cdot \mathrm{s}\right.$ at $\left.25^{\circ} \mathrm{C}\right)$ of the adhesive, which, in contact with porous substrates (MDF) and oak veneer, intensely penetrated both materials. Subsequently, it is likely that too thin bondline was formed. Unlike for MDF substrate, C0\% PUR penetration into less porous solid wood in lap shear specimens was weaker, which resulted in an improved bondline performance. Viscosity increase to $19.7 \mathrm{~Pa} \cdot \mathrm{s}$ due to silica addition impeded overpenetration of the adhesive into substrates. 


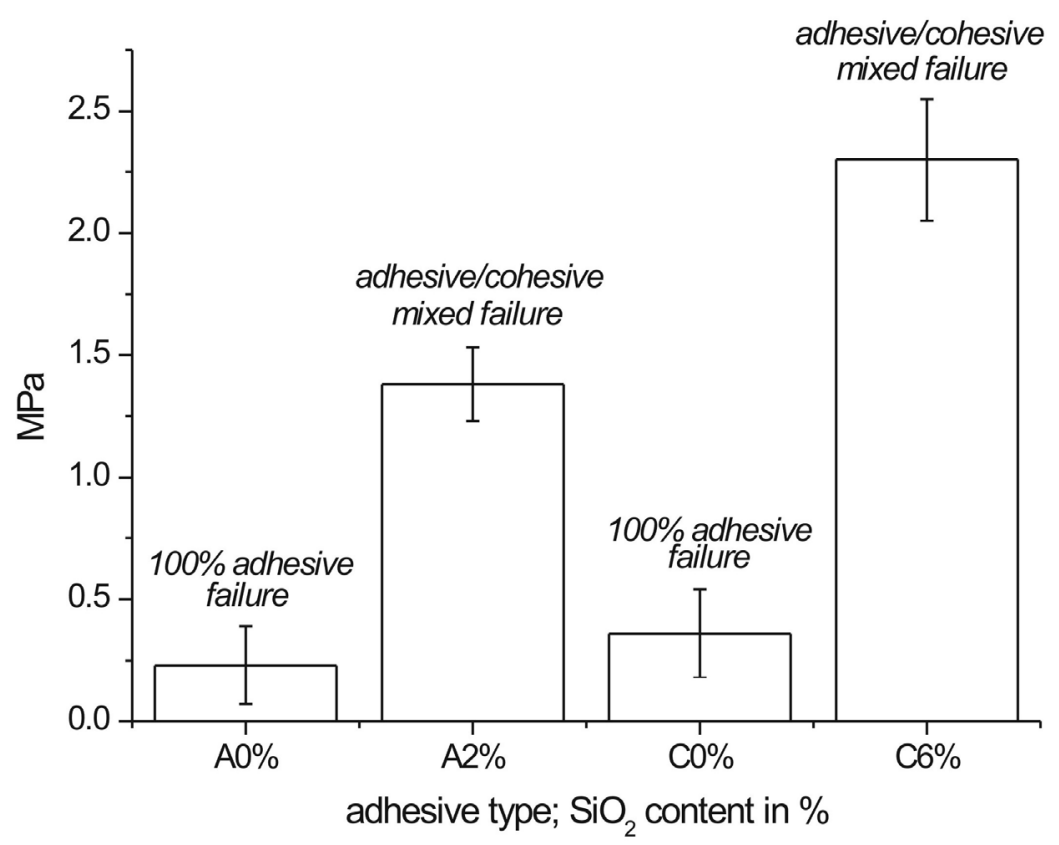

Figure 6. Bondline strength in pull-off tests performed on medium density fiberboard (MDF) veneered with $0.6-\mathrm{mm}$ thick oak veneer.

\subsection{Thermal Properties}

Thermogravimetric experiments revealed (Table 5, Figure S3) that the presence of silica affects thermal degradation of the polymers. In all cases temperatures of a indicated weight loss were shifted to a lower value. It is surprising as the increase in PUR thermal stability in the presence of silica has been recognized in the literature $[54,55]$.

Table 5. Thermal stability of the studied PURs.

\begin{tabular}{ccccc}
\hline \multirow{2}{*}{ Sample } & \multicolumn{2}{c}{ Temperature of Weight Loss $\left[{ }^{\circ} \mathrm{C}\right]$} & \multirow{2}{*}{$\begin{array}{c}\text { Residual Weight } \\
\text { at } \mathbf{8 0 0}{ }^{\circ} \mathbf{C}[\%]\end{array}$} \\
\cline { 2 - 4 } & $\mathbf{5 \%}$ & $\mathbf{5 0 \%}$ & $\mathbf{8 0 \%}$ & 1.21 \\
\hline $\mathrm{A} 0 \% \mathrm{SiO}_{2}$ & 207.8 & 421.2 & 592.4 & 3.87 \\
$\mathrm{~A} 2 \% \mathrm{SiO}_{2}$ & 189.0 & 406.1 & 580.4 & 1.20 \\
$\mathrm{C} 0 \% \mathrm{SiO}_{2}$ & 163.3 & 387.3 & 567.3 & 6.25 \\
$\mathrm{C} 6 \% \mathrm{SiO}_{2}$ & 156.2 & 367.7 & 559.5 & \\
\hline
\end{tabular}

DTA curves shown in Figure 7 indicate that the endothermic peaks in region $110-125{ }^{\circ} \mathrm{C}$ correspond to dehydration of polymers while exothermic peaks around $554.2-576.3^{\circ} \mathrm{C}$ are associated with thermooxidation. MS results coupled with TG presented in Figure S3 proved that the main thermooxidation products are water $(\mathrm{m} / \mathrm{z} 18)$ and $\mathrm{CO}_{2}(\mathrm{~m} / \mathrm{z} 44)$. Maximum water evolution was found at $390.2{ }^{\circ} \mathrm{C}$ and $400.5{ }^{\circ} \mathrm{C}$ for the $\mathrm{A} 0 \% \mathrm{SiO}_{2}$ and $\mathrm{A} 2 \% \mathrm{SiO}_{2}$ PURs, respectively, and at $380.3{ }^{\circ} \mathrm{C}$ and 359.2 ${ }^{\circ} \mathrm{C}$ for the $\mathrm{C} 0 \% \mathrm{SiO}_{2}$ and $\mathrm{C} 6 \% \mathrm{SiO}_{2}$ PURs. Maxima for carbon dioxide evolution were observed at $597.4{ }^{\circ} \mathrm{C}$ for $\mathrm{C} 0 \% \mathrm{SiO}_{2}$ PUR and at $566.9^{\circ} \mathrm{C}$ for $\mathrm{C} 6 \% \mathrm{SiO}_{2}$ PUR.

From the practical point of view the changes in thermal stability of the PURs can be neglected as in the area of their target application high thermal resistance is not required. 


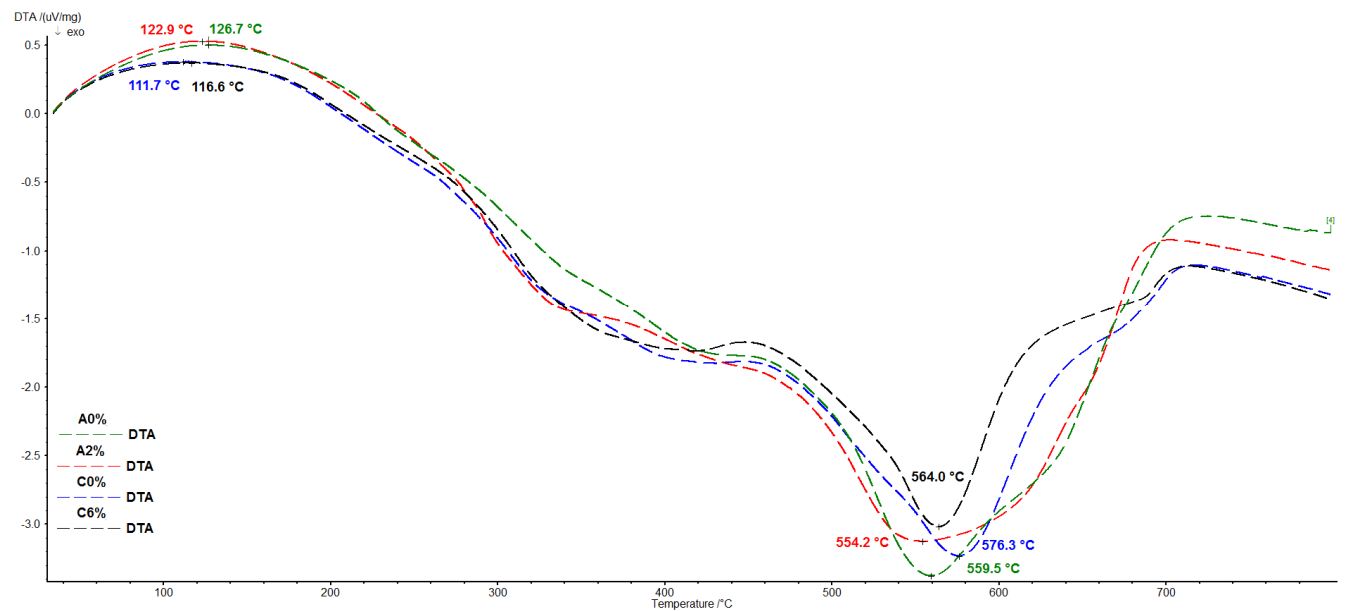

Figure 7. DTA curves for the investigated PURs.

\section{Conclusions}

The presented results clearly demonstrate that polyglycerol- and sucrose-based polyols can be considered renewable resource-based materials for 2-component polyurethane adhesive formulations. It has been shown that the properties of the adhesives (reactivity and bonding strength) of a formulation simplified to one polyol can be easily tuned by silica so that become applicable in industrial veneering operations.

The observations also revealed that small additions of colloidal silica used as a viscosity control agent decreased PURs reactivity and thermal stability, but on the other hand, improved adhesion interactions with the substrate, reinforced polymers, and increased bondline strengths.

Therefore, the polyglycerol- and sucrose-based polyols seem useful raw materials for further development and optimization of adhesives to be implemented in furniture industry.

Supplementary Materials: The following are available online at http://www.mdpi.com/2073-4360/12/10/2177/s1, Figure S1: NMR and FTIR spectra of the polyglycerol; Figure S2: Representative adhesive and substrate failure; Figure S3: TG and MS curves of the studied PURs.

Author Contributions: Conceptualization, M.Ł.M.; investigation, A.M.W.-M., P.G.P., and M.Ł.M.; writing—original draft preparation, M.Ł.M.; supervision, M.Ł.M.; data curation, A.M.W.-M., and M.Ł.M.; All authors have read and agreed to the published version of the manuscript.

Funding: This research was funded by The National Centre for Research and Development (grant no. TANG0 1/266389/NCBR/2015).

Acknowledgments: Authors gratefully thank Ultrapur Sp. z o.o. (Poznań, Poland) for kind donation of the sucrose polyol and PMDI.

Conflicts of Interest: The authors declare no conflict of interest.

\section{References}

1. Tohmura, S.; Li, G.; Qin, E. Preparation and characterization of wood polyalcohol-based isocyanate adhesives. J. Appl. Polym. Sci. 2005, 98, 791-795. [CrossRef]

2. Juhaida, M.F.; Paridah, M.T.; Mohd Hilmi, M.; Sarni, Z.; Jalaluddin, H.; Mohamad Zaki, A.R. Liquefaction of kenaf (Hibiscus cannabinus L.) core for wood laminating adhesive. Bioresour. Technol. 2010, 101, 1355-1360. [CrossRef] [PubMed]

3. Pan, H.; Zheng, Z.; Hse, C.Y. Microwave-assisted liquefaction of wood with polyhydric alcohols and its application in preparation of polyurethane (PU) foams. Eur. J. Wood Prod. 2012, 70, 461-470. [CrossRef]

4. Lee, W.J.; Chao, C.Y. Effect of containing polyhydric alcohol liquefied wood on the properties of thermoplastic polyurethane resins. Eur. J. Wood Prod. 2018, 76, 1745-1752. [CrossRef] 
5. Borowicz, M.; Paciorek-Sadowska, J.; Lubczak, J.; Czupryński, B. Biodegradable, flame-retardant, and bio-based rigid polyurethane/polyisocyanurate foams for thermal insulation application. Polymers 2019, 11, 1816. [CrossRef]

6. Zhao, C.; Huang, C.; Chen, Q.; Ingram, I.D.V.; Zeng, X.; Ren, T.; Xie, H. Sustainable aromatic aliphatic polyesters and polyurethanes prepared from vanillin-derived diols via green catalysis. Polymers 2020, 12, 586. [CrossRef]

7. Ivdre, A.; Abolins, A.; Sevastyanova, I.; Kirpluks, M.; Cabulis, U.; Merijs-Meri, R. Rigid polyurethane foams with various isocyanate indices based on polyols from rapeseed oil and waste PET. Polymers 2020, 12, 738. [CrossRef]

8. Alinejad, M.; Henry, C.; Nikafshar, S.; Gondaliya, A.; Bagheri, S.; Chen, N.; Singh, S.K.; Hodge, D.B.; Nejad, M. Lignin-based polyurethanes: Opportunities for bio-based foams, elastomers, coatings and adhesives. Polymers 2019, 11, 1202. [CrossRef]

9. Anastas, P.T.; Warner, J.C. Green Chemistry: Theory and Practice; Oxford University Press: New York, NY, USA, $1998 ;$ p. 12.

10. Da Silva, G.P.; Mack, M.; Contiero, J. Glycerol: A promising and abundant carbon source for industrial microbiology. Biotechnol. Adv. 2009, 27, 30-39. [CrossRef]

11. Behr, A.; Eilting, J.; Irawadi, K.; Leschinski, J.; Lindner, F. Improved utilization of renewable resources: New important derivatives of glycerol. Green Chem. 2008, 10, 13-30. [CrossRef]

12. Nagy, L.; Nagy, M.; Vadkerti, B.; Daróczi, L.; Deák, G.; Zsuga, M.; Kéki, S. Designed polyurethanes for potential biomedical and pharmaceutical applications: Novel synthetic strategy for preparing sucrose containing biocompatible and biodegradable polyurethane networks. Polymers 2019, 11, 825. [CrossRef]

13. Gama, N.V.; Amaral, C.; Silva, T.; Vicente, R.; Pereira Coutinho, J.A.; Barros-Timmons, A.; Ferreira, A. Thermal energy storage and mechanical performance of crude glycerol polyurethane composite foams containing phase change materials and expandable graphite. Materials 2018, 11, 1896. [CrossRef] [PubMed]

14. Hu, S.; Li, Y. Two-step sequential liquefaction of lignocellulosic biomass by crude glycerol for the production of polyols and polyurethane foams. Bioresour. Technol. 2014, 161, 410-415. [CrossRef] [PubMed]

15. Savelyev, Y.; Markovskaya, L.; Savelyeva, O.; Akhranovich, E.; Parkhomenko, N.; Travinskaya, T. Degradable polyurethane foams based on disaccharides. J. Appl. Polym. Sci. 2015, 132, 42131. [CrossRef]

16. Globe Newswire. Industrial Sugar Market to Reach USD 45.6 Billion by 2027. Reports and Data. 29 July 2020. Available online: https://www.globenewswire.com/news-release/2020/07/29/2069858/0/en/Industrial-SugarMarket-To-Reach-USD-45-6-Billion-By-2027-Reports-and-Data.html (accessed on 25 August 2020).

17. Deng, S.; Pizzi, A.; Du, G.; Lagel, M.C.; Delmotte, L.; Abdalla, S. Synthesis, structure characterization and application of melamine-glyoxal adhesive resins. Eur. J. Wood Prod. 2018, 76, 283-296. [CrossRef]

18. Santiago-Medina, F.; Foyer, G.; Pizzi, A.; Caillol, S.; Delmotte, L. Lignin-derived non-toxic aldehydes for ecofriendly tannin adhesives for wood panels. Int. J. Adhes. Adhes. 2016, 70, 239-248. [CrossRef]

19. Zhao, Z.; Sakai, S.; Wu, D.; Chen, Z.; Zhu, N.; Huang, C.; Sun, S.; Zhang, M.; Umemura, K.; Yong, Q. Further exploration of sucrose-citric acid adhesive: Investigation of optimal hot-pressing conditions for plywood and curing behavior. Polymers 2019, 11, 1996. [CrossRef]

20. Sun, S.; Zhao, Z.; Umemura, K. Further Exploration of sucrose-citric acid adhesive: Synthesis and application on plywood. Polymers 2019, 11, 1875. [CrossRef]

21. Jasiūnas, L.; Peck, G.; Bridžiuvienè, D.; Miknius, L. Mechanical, thermal properties and stability of high renewable content liquefied residual biomass derived bio-polyurethane wood adhesives. Int. J. Adhes. Adhes. 2020, 101, 102618. [CrossRef]

22. Tenorio-Alfonso, A.; Carmen Sánchez, M.; Franco, J.M. Preparation, characterization and mechanical properties of bio-based polyurethane adhesives from isocyanate-functionalized cellulose acetate and castor oil for bonding wood. Polymers 2017, 9, 132. [CrossRef]

23. Desroches, M.; Escouvois, M.; Auvergne, R.; Caillol, S.; Boutevin, B. From vegetable oils to polyurethanes: Synthetic routes to polyols and main industrial products. Polym. Rev. 2012, 52, 38-79. [CrossRef]

24. EN 312 Particleboards—Specifications; European Committee for Standardization: Brussels, Belgium, 2011.

25. EN 622 Fiberboards—Specifications; European Committee for Standardization: Brussels, Belgium, 2006.

26. Moubarik, A.; Pizzi, A.; Allal, A.; Charrier, F.; Khoukh, A.; Charrier, B. Cornstarch-Mimosa tannin-Urea formaldehyde resins as adhesives in the particleboard production. Starch-Stärke 2010, 62, 131-138. [CrossRef] 
27. Bahattab, M.A.; Donate-Robles, J.; García-Pacios, V.; Martín-Martínez, J.M. Characterization of polyurethane adhesives containing nanosilicas of different particle size. Int. J. Adhes. Adhes. 2011, 31, 97-103. [CrossRef]

28. Randall, D.; Lee, S. (Eds.) The Polyurethanes Book; Wiley: New York, NY, USA, 2002.

29. Evance, A.G. The strength of brittle materials containing second phase dispersions. Phil. Mag. 1972, 26, 1327-1344. [CrossRef]

30. Green, D.G.; Nicholson, P.S.; Embury, J.D. Fracture of a brittle particulate composite, Part 2: Theoretical aspects. J. Mater. Sci. 1979, 14, 1657-1661. [CrossRef]

31. Imanaka, M.; Takeuchi, Y.; Nakamura, Y.; Nishimura, A.; Iida, T. Fracture toughness of spherical silica-filled epoxy adhesives. Int. J. Adhes. Adhes. 2001, 21, 389-396. [CrossRef]

32. Petrović, Z.S.; Javni, I.; Waddon, A.; Banhegyi, G. Structure and properties of polyurethane-Silica nanocomposites, J. Appl. Polym. Sci. 2000, 76, 133-151. [CrossRef]

33. He, H.; Pang, Y.; Duan, Z.; Luo, N.; Wang, Z. The Strengthening and toughening of biodegradable poly (lactic acid) using the SiO2-PBA core-Shell nanoparticle. Materials 2019, 12, 2510. [CrossRef]

34. Torró-Palau, A.M.; Fernández-García, J.C.; Orgilés-Barceló, A.C.; Martín-Martínez, J.M. Characterization of polyurethanes containing different silicas. Int. J. Adhes. Adhes. 2001, 21, 1-9. [CrossRef]

35. Kuriyagawa, M.; Kawamura, T.; Hayashi, S.; Nitta, K.-H. Reinforcement of polyurethane-based shape memory polymer by hindered phenol compounds and silica particles. J. Appl. Polym. Sci. 2010, 117, 1695-1702. [CrossRef]

36. Rokicki, G.; Rakoczy, P.; Parzuchowski, P.; Sobiecki, M. Hyperbranched aliphatic polyethers obtained from environmentally benign monomer: Glycerol carbonate. Green Chem. 2005, 7, 529-539. [CrossRef]

37. Mamiński, M.; Parzuchowski, P.; Trojanowska, A.; Dziewulski, S. Fast-curing polyurethane adhesives derived from environmentally friendly hyperbranched polyglycerols-The effect of macromonomer structure. Biomass Bioenerg. 2011, 35, 4461-4468. [CrossRef]

38. EN 205 Adhesives. Wood Adhesives for Non-Structural Applications. Determination of Tensile Shear Strength of Lap Joints; European Committee for Standardization: Brussels, Belgium, 2003.

39. EN 311 Wood-Based Panels—Surface Soundness-Test Method; European Committee for Standardization: Brussels, Belgium, 2002.

40. Wolkenhauer, A.; Avramidis, G.; Hauswald, E.; Militz, H.; Viöl, W. Sanding vs. plasma preatment of aged wood: A comparison with respect to surface energy. Int. J. Adhes. Adhes. 2009, 29, 18-22. [CrossRef]

41. Gindl, M.; Sinn, G.; Gindl, W.; Reiterer, A.; Tschegg, S. A comparison of different methods to calculate the surface free energy of wood using contact angle measurements. Colloid. Surface. A 2001, 181, 279-287. [CrossRef]

42. Chiacchiarelli, L.M.; Puri, I.; Puglia, D.; Kenny, J.M.; Torre, L. Cure kinetics of a highly reactive silica-Polyurethane nanocomposite. Thermochim. Acta 2012, 549, 172-178. [CrossRef]

43. Mamiński, M. Effect of hydroxyl functionality of branched polyol component on PUR curing thermal effect. Ann. Warsaw Univ. Life Sci. SGGW For. Wood Technol. 2012, 78, 238-242.

44. Lengyel, K.; Barbu, M.C.; Campean, M.; Badin, N.; Bedelean, B. Improving properties of particleboards with reduced density. Bioresources 2018, 13, 1289-1302. [CrossRef]

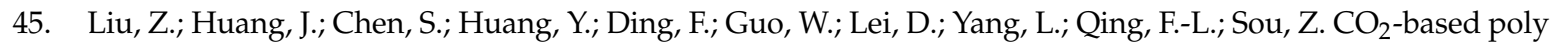
(propylene carbonate) with various carbonate linkage content for reactive hot-melt polyurethane adhesives. Int. J. Adhes. Adhes. 2020, 96, 102456. [CrossRef]

46. Liu, Z.-H.; Huang, J.-Q.; Sun, L.-J.; Lei, D.; Cao, J.; Chen, S.; Shih, W.-C.; Qing, F.-L.; Sou, Z.-W. PPC-based reactive hot melt polyurethane adhesive (RHMPA)—Efficient glues for multiple types of substrates. Chin. J. Polym. Sci. 2018, 36, 58-64. [CrossRef]

47. Malaki, M.; Hashemzadeh, Y.; Karevan, M. Effect of nano-silica on the mechanical properties of acrylic-polyurethane coatings. Prog. Org. Coat. 2016, 101, 477-485. [CrossRef]

48. Sernek, M.; Boonstra, M.; Pizzi, A.; Despres, A.; Gerardin, P. Bonding performance of heat treated wood with structural adhesives. Holz Roh. Werkst. 2008, 66, 173-180. [CrossRef]

49. Nuñes, R.; Fonseca, J.; Pereira, M. Polymer-filler interactions and mechanicalproperties of a polyurethane elastomer. Polym. Test. 2000, 19, 93-103. [CrossRef]

50. Serkis, M.; Špirková, M.; Kredatusova, J.; Hodan, J.; Bureš, R. Organic-inorganic nanocomposite films made from polyurethane dispersions and colloidal silica particles. Compos. Interface 2016, 23, 157-173. [CrossRef] 
51. Chen, L.; Wang, X.; Jia, Z.; Luo, Y.; Jia, D. Use of precipitated silica with silanol groups as an inorganic chain extender in polyurethane. Mater. Design. 2015, 87, 324-330. [CrossRef]

52. Beck, G.; Hill, C.; Cocher, P.M.; Alfredsen, G. Accessibility of hydroxyl groups in furfurylated wood at different weight percent gains and during Rhodonia placenta decay. Eur. J. Wood Prod. 2019, 77, 953-955. [CrossRef]

53. Qin, R.-Y.; Schreiber, H.P. Adhesion at partially restructured polymer surfaces. Colloid. Surface 1999, 156, 85-93. [CrossRef]

54. Meera, K.M.S.; Sankar, M.R.; Paul, J.; Jaisankar, S.N.; Manda, A.B. The influence of applied silica nanoparticles on a bio-renewable castor oil based polyurethane nanocomposite and its physicochemical properties. Phys. Chem. Chem. Phys. 2014, 16, 9276-9288. [CrossRef]

55. Vega-Baudrit, J.; Sibaja-Ballestero, M.; Vázquez, P.; Nuñez, S.; Martín-Martínez, J.M.; Benavides-Rodríguez, L. Kinetics of isothermal degradation studies in adhesives by thermogravimetric data: Effect of hydrophilic nanosilica fillers on the thermal properties of thermoplastic polyurethane-silica nanocomposites. Recent Pat. Nanotech. 2008, 2, 220-226. [CrossRef]

(C) 2020 by the authors. Licensee MDPI, Basel, Switzerland. This article is an open access article distributed under the terms and conditions of the Creative Commons Attribution (CC BY) license (http://creativecommons.org/licenses/by/4.0/). 